\title{
Síntesis
}

\section{LAS VITAMINAS}

El descubridor de las vitaminas fue el polaco Casimir Funk (1884-1976), su experiencia fue posible gracias a los estudios efectuados previamente por el médico Christian Eijkman (18551930), que había investigado la importancia del cascabillo del arroz en la curación y prevención del beriberi, una enfermedad neurológica debida a carencias alimentarlas y particularmente difundida en Asia.

A raíz de estas investigaciones, Funk logró aislar a partir del arroz un principio activo al que le denominó TIAMINA. Es la

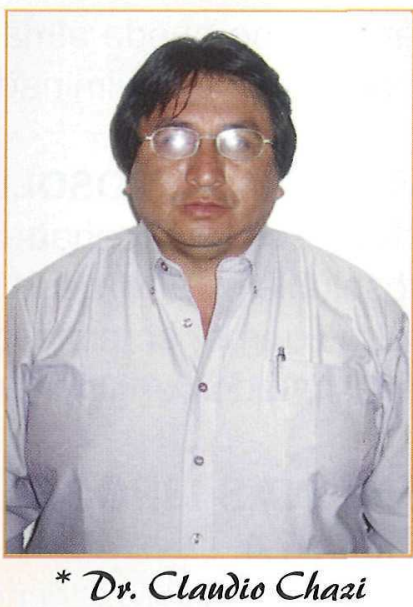
primera vitamina que se logró aislar bautizándola con el nombre de vitamina B1. El termino vitamina fue acuñado mediante la unión de las voces "vida" y "amina", el género
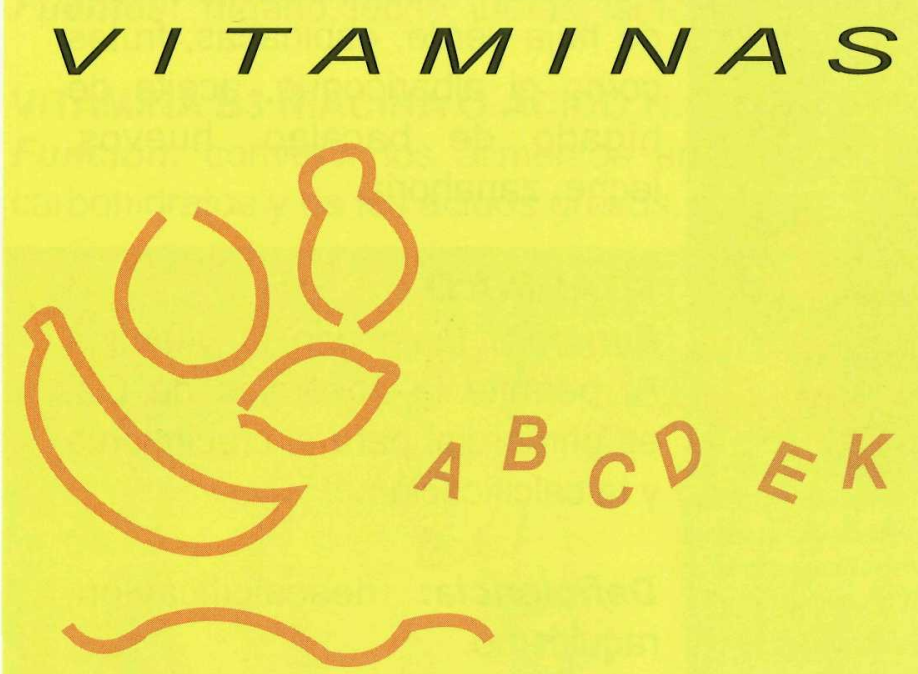
químico de la sustancia.

Las vitaminas son nutrientes necesarios para el buen funcionamiento celular del organismo y, a diferencia de algunos minerales, actúan en dosis muy pequeñas. Como nuestro cuerpo no puede fabricarlas por sí mismo, lo nutritivo de los alimentos no se podría aprovechar ya que activan la oxidación de la comida, las operaciones metabólicas y facilitan la utilización y liberación de energía proporcionada a través de los alimentos. De esta manera es fácil darse cuenta de la importancia que conlleva este esencial compuesto orgánico para el completo estado de vitalidad celular, lo que conllevaría a un estado de bienestar anatómico y fisiológico de la célula, de allí la necesidad permanente de que este compuesto siempre esté en la dieta o alimentación cotidiana, pues son para nosotros "LA CHISPA QUE ENCIENDE EL FUEGO".

Cada célula del cuerpo tiene la función de transformar los aminoácidos, minerales y oligoelementos en proteínas, hormonas y enzimas. Algunas vitaminas forman parte de estas enzimas, por lo que resultan indispensables para el funcionamiento corporal. De las 13 vitaminas diferentes que se conocen actualmente, podemos diferenciar dos grupos distintos:

1) VITAMINAS HIDROSOLUBLES:

Como la vitamina $C$ y las del complejo B. B1,B2,B6;B12, NACINA, ÁCIDO FÓLICO, ÁCIDO PANTOTÉNICO Y BIOTINA), que se disuelven en el agua y como el 
El peor mal es un corazón vacío...

organismo no puede almacenarlas, es necesario un aporte diario o controlado debido a que el exceso es eliminado por el sudor y la orina.

2) VITAMINAS LIPOSOLUBLES: se disuelven en grasas como las vitaminas $A, D, E$, $K$. Estas se almacenan en los tejidos adiposos y en el hígado, se diferencian de las hidrosolubles. El exceso de consumo puede ser muy perjudicial para la salud, ya que nuestro cuerpo sí almacena su exceso. Tanto la carencia como el exceso de algunas de ellas pueden originar enfermedades irreversibles.

\section{VITAMINAS LIPOSOLUBLES VITAMINA A}

Función: ayuda al crecimiento y la visión .

Deficiencia: disminución de la visión en penumbra, piel seca, picazón en los ojos, uñas quebradizas.

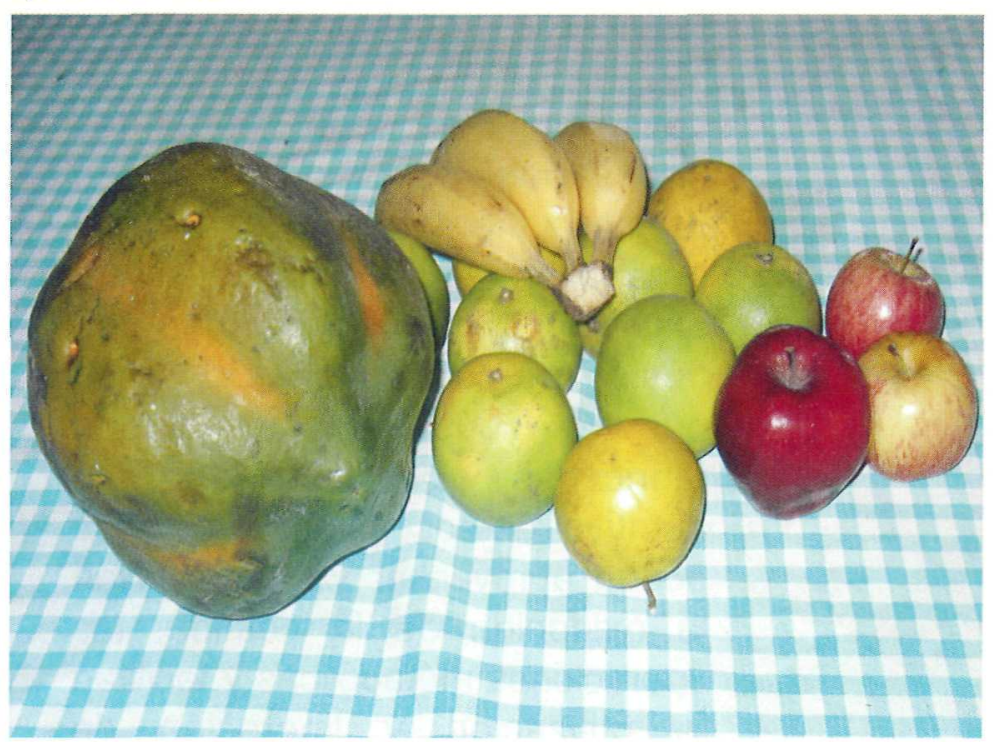

Fuentes: mantequilla, hortalizas de hoja verde, espinacas, frutas como el albaricoque, aceite de hígado de bacalao, huevos, leche, zanahoria.

\section{VITAMINA D}

Función: junto con la vitamina A, permite la absorción de $\mathrm{Ca}$, es primordial para el crecimiento y la calcificación.

Deficiencia: descalcificación, raquitismo.

Fuentes: pescado, hígado, productos lácteos, huevos, la luz solar, cuyos rayos ultravioleta favorecen la absorción y asimilación de pro vitaminas en vitamina $\mathrm{D}$.

\section{VITAMINA E}

Función: facilita la circulación sanguínea, y estabiliza las hormonas femeninas, favoreciendo el embarazo y parto.

Deficiencia: anemia en niños prematuros.

Fuentes: frutos secos, huevos, mantequilla , espárragos, soya, espinaca y judías.

\section{VITAMINA K}

Función: actúa sobre la coagulación.

Deficiencia: alteraciones en la coagulación sanguínea.

Fuentes: patatas, coliflor, judías verdes, guisantes frescos y las espinaca. 


\section{VITAMINAS HIDROSOLUBLES:}

\section{VITAMINA B1 O TIAMINA}

Función: liberar energía que contienen los hidratos de carbono.

Deficiencia: disminuye la glucosa en la sangre, fatiga, irritabilidad, debilidad muscular, falta de concentración o voluntad.

Fuentes: frutos secos, cereales integrales, leguminosas, levadura de cerveza y germen de trigo.

\section{VITAMINA B2 O RIBOFLAVINA}

Función: catalizar la oxidación de grasas, proteínas e hidratos de carbono.

Deficiencia: trastornos visuales, inflamación de la mucosa bucal y garganta.

Fuentes: hígado, leche, judías, lentejas, quesos y frutos secos.

\section{VITAMINA B3 NIACINA O ÁCIDO NICOTÍNICO}

Función: convertir los alimentos en energía. Se le implica en la oxidación de los carbohidratos y de los ácidos grasos.

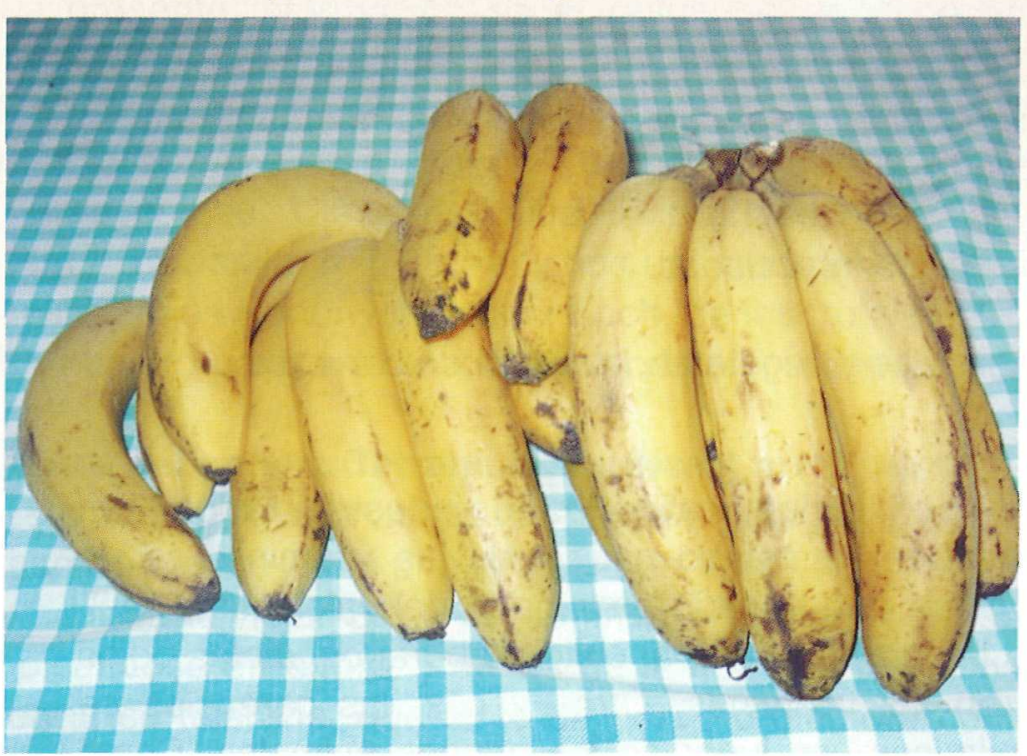

Deficiencia: produce la Pelagra.

Fuentes: leguminosas, frutos secos, cereales, levadura de cerveza.

\section{VITAMINA B6 O PIRIDOXINA}

Función: metabolismo de aminoácidos y formación de hemoglobina.

Deficiencia: no parece tener mayor incidencia en los problemas dietéticos.

Fuentes: plátanos, aguacates, cereales integrales, vegetales en general.

\section{VITAMINA B9, M, ÁCIDO FOLICO O FOLACINA}

Función: interviene en la sintesis de ADN en las células de tejidos nuevos , como es el caso de los fetos, también interviene en la formación de glóbulos rojos.

Deficiencia: la carencia de esta vitamina induce a un tipo de anemia que impide el crecimiento de los glóbulos rojos.

Fuentes: lenteja, judías, verduras, hígado. 
VITAMINA B12 O CIANOCOBALAMINA:

Función: formación de glóbulos rojos.

Deficiencia: daño en las células nerviosas y anemia perniciosa.

Fuentes: hígado. Es la única vitamina que tiene una molécula con un mineral, el cobalto, y no lo produce ninguna planta o animal, sino solo algunos microorganismos.

\section{LA VITAMINA C O ÁCIDO ASCÓRBICO}

Función: formación de la proteína de los tejidos conjuntivos y regeneración del cartílago de los huesos.

Deficiencia: aberturas del tejido conjuntivo, hemorragias subcutáneas, dificultad en la cicatrización de las fracturas o la caída de dientes.

Fuentes: papas, hortalizas crudas, frutas cítricas, tomates, pimientos, espinacas.

LA VITAMINA H O BIOTINA: se encuentra en muchos alimentos vegetales y animales, por lo que no suelen ofrecer problemas dietéticos.

Fuente: hígado de ternera y cerdo, yema de huevo, espinacas, levadura de cerveza.

\section{EL ÁCIDO PANTOTÉNICO:}

Función: defensa del organismo contra infecciones, interviene en el metabolismo de grasas, proteína e hidratos de carbono.

Deficiencia: disminuye las defensas contra infecciones.

Fuentes: está en todos los tejidos animales y vegetales, levadura de cerveza .

\section{¿CANTIDAD O CALIDAD?}

Cada vez más los alimentos son purificados, refinados e industrializados con tratamientos que mejoran la conservación; el estado natural de las vitaminas se ve alterado y cuando llegan a nuestra mesa han perdido gran parte del valor nutricional. Los desequilibrios alimenticios como la comida chatarra, salto de horarios, dietas bajas en calorías, producen disminución en las vitaminas. Otras veces, las carencias se relacionan con el uso de abonos químicos en lugar de los abonos animales. Como nutrientes del organismo, las vitaminas son esenciales para la vida. La mejor manera de consumirlas es al natural y según la variación en función del contenido vitamínico.

\section{BIBLIOGRAFIA:}

ENCICLOPEDIA DEL CONOCIMIENTO . Tomo 7. Biología I. Pág. 22-24.

GUIA MEDICA FAMILIAR. Tomo I. Pág.13-15.

BIOLOGÍA DE CURTIS HELENA. V Edición. Editorial Latinoamericana.

MENTOR INTERACTIVO ENCICLOPEDIA. Temática Estudiantil.

ENCICLOPEDIA SUPERIOR. Círculo de Lectores.

* Catedrático de Biología y Microbiología 